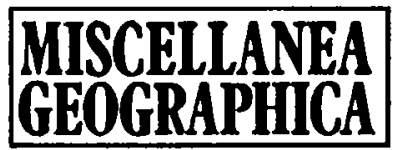

WARSZAWA 1996 Vol. 7

Richard Mbewe

\title{
THE PhS FERTILIZER USAGE IN ZAMBIA*
}

\author{
INTRODUCTION
}

The main nutrients in phosphate fertilizers are calcium, phosphorus and sulphur. These three nutrients are very valuable in plant nutrition and their presence in a given type of soil is no question. In case of soils presenting a deficiency of these plant nutrients, phosphate fertilizers are applied to the soil. The release of these nutrients is very important in cases of soils in which the erosion or high-leaching take place. Therefore, the slow-release of these nutrients is advantageous in the sense that the roots of the plant have enough time to absorb the nutrients and use them in plant growth (Mbewe 1991).

There are types of fertilizers that tend to have this characteristic. Among them is the $\mathrm{PhS}$ fertilizer - named after the main components phosphorus and sulphur.

The $\mathrm{PhS}$ fertilizer is a fertilizer containing the macronutrients phosphorus, sulphur and calcium. The characteristic of the $\mathrm{PhS}$ fertilizer is the slow-release of these three components. The fertilizer is an appropriate mixture of all components needed to produce soluble phosphates from rock phosphates and sulphur with an inoculated bioactive agent. Bioactive agent is a medium carrier of bacteria of the genus Thiobacillus thio-oxidans which are mainly responsible for the bioxidation of element sulphure to sulfuric acid (Urbanek 1978). The biochemical reaction is as follows:

$$
\mathrm{S}+3 / 2 \mathrm{O}_{2}+\mathrm{H}_{2} \mathrm{O} \mathrm{H}_{2} \mathrm{SO}_{4}
$$

The sulfuric acid produced by the bacteria reacts with the components of the rock phosphate to form water soluble $\mathrm{P}_{2} \mathrm{O}_{5}$.

* Part of PhD thesis "The sustainable usage of agrochemicals in developing countries - a case of Zambia”, prepared under the direction of Professor Janusz Gudowski at the Faculty of Geography and Regional Studies. 
The most important feature of the PhS fertilizer is that the processing of the rock phosphate it contains proceeds in the soil after fertilizer application by the farmer. The composition and preparation procedure assures a high ratio of bio as well as chemical dissolution processes of the fertilizer grains in the soil. The concentration of phosphorus released is sufficiently high to meet with the requirements of plants growing at the same time as conversion of the $\mathrm{PhS}$ fertilizer in the soil is taking place.

\section{PRODUCTION PROCESS OF PhS}

The production of the $\mathrm{PhS}$ fertilizer involves the following processes:

- grinding of rock phosphate to minus 100 mesh

- crushing and grinding of elemental sulphur

- heating ground rock phosphate (GRP)

- mixing of GRP with melting elemental sulphur

- cooling of the PhS

- inoculation of $\mathrm{PhS}$ production with bioactive agent.

The product $-\mathrm{PhS}$ fertilizer, is a coarse grained powder having $80 \%$ grains within the range $0.1-1.0 \mathrm{~mm}$. It can be bagged directly after preparation or can be stored and handled in bulk. Rocks having high sesquioxides $\left(\mathrm{R}_{2} \mathrm{O}_{3}\right.$ where $\left.\mathrm{R}=\mathrm{Fe}, \mathrm{Al}\right)$ chlorides, silica and carbonate contents can be used. The concentration of impurities only has an influence on the sulphur consumption rate per tone of $\mathrm{P}_{2} \mathrm{O}_{5}$ in the fertilizer.

Elemental sulphur of low quality (recovered sulphur) or even sulphur ores of low grade can be utilized as well. The process is designed for countries with developing phosphate fertilizer industries as well as for industrialized ones which major objectives might be production of phosphate fertilizer without toxic waste and environmental pollutants.

\section{THE AGRICULTURAL FEATURES OF THE PhS FERTILIZER}

The agricultural features of the $\mathrm{PhS}$ fertilizer are in accordance with the latest scientific and practical requirements formulated for modern phosphate fertilizers. $\mathrm{PhS}$ fertilizer exhibits:

- slow release of $\mathrm{P}_{2} \mathrm{O}_{5}$ from the fertilizer to the soil - resistance to phosphorus fixation seasons

- prolonged action of phosphorus; it can be applied after three cropping

- neutral reaction to soil, it does not change the $\mathrm{pH}$ of the soil.

$\mathrm{PhS}$ fertilizer acts on sporadic patches of thin films of elemental sulphur on the source of the GRP as a distinct physical feature for differentiation of the PhS fertilizer from other fertilizers. The feature creates accessibility of 


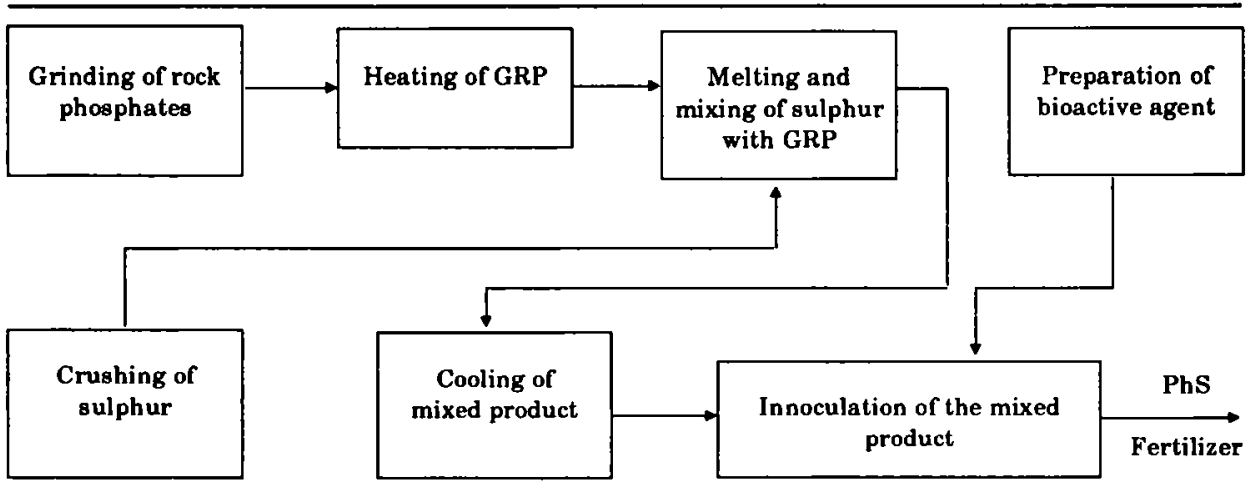

Source: Urbanek, 1978.

Fig. 1. Flowsheet diagram showing stages involved in $\mathrm{PhS}$ fertilizer production

oxygen to the bacteria adhering to the surface of elemental sulphur assuring their continuous biological evolution of sulfuric acid. Since sulfuric acid generated biologically is in direct contact with the GRP surface, immediate digestion of GRP could result, preventing instant acidification of the soil in its vicinity. The $\mathrm{PhS}$ fertilizer could in this way provide both immediate and long term utilities for crops that can be used for fertilization.

The $\mathrm{PhS}$ fertilizer can also compare favourably with the traditional fertilizers like single and/or triple superphosphate, mono- and/or diammonium phosphate, or even nitrophosphate. In soils saturated with moisture, the high dissolution rate of $\mathrm{P}_{2} \mathrm{O}_{5}$ in these fertilizers could lead to the abundance of $\mathrm{P}_{2} \mathrm{O}_{5}$ in the soil but only for a short period of time. Thereafter, only a little fraction determinable by the soil equilibrium condition is left while the rest becomes fixed. The $\mathrm{PhS}$ fertilizer had been used, the gradual release of $\mathrm{P}_{2} \mathrm{O}_{5}$ is accompanied by its systematic uptake by crops assuring efficient utilization of all resources used (Ekechukwu 1990).

Samples of rock phosphate from Zambia were tested for their suitability as $\mathrm{PhS}$ fertilizer. These samples were from two sites in Zambia - Mumbwa North and from Chilembwe-Sinda West. Both samples showed positive reactions to the $\mathrm{PhS}$ fertilizer process. Chilembwe-Sinda West sample showed the most positive and promising response as shown in Figures 2 and 3.

\section{THE PhS FERTILIZERS AND ALLIED PRODUCTS}

The term allied products is used here to describe collectively the group of fertilizers that release phosphorus and sulphur slowly, i.e., they are slowrelease fertilizers. A collection of allied products included a wide range of mixtures of GRP and elemental sulphur distinct from $\mathrm{PhS}$ fertilizer. An outline of different types of allied products is presented below: 


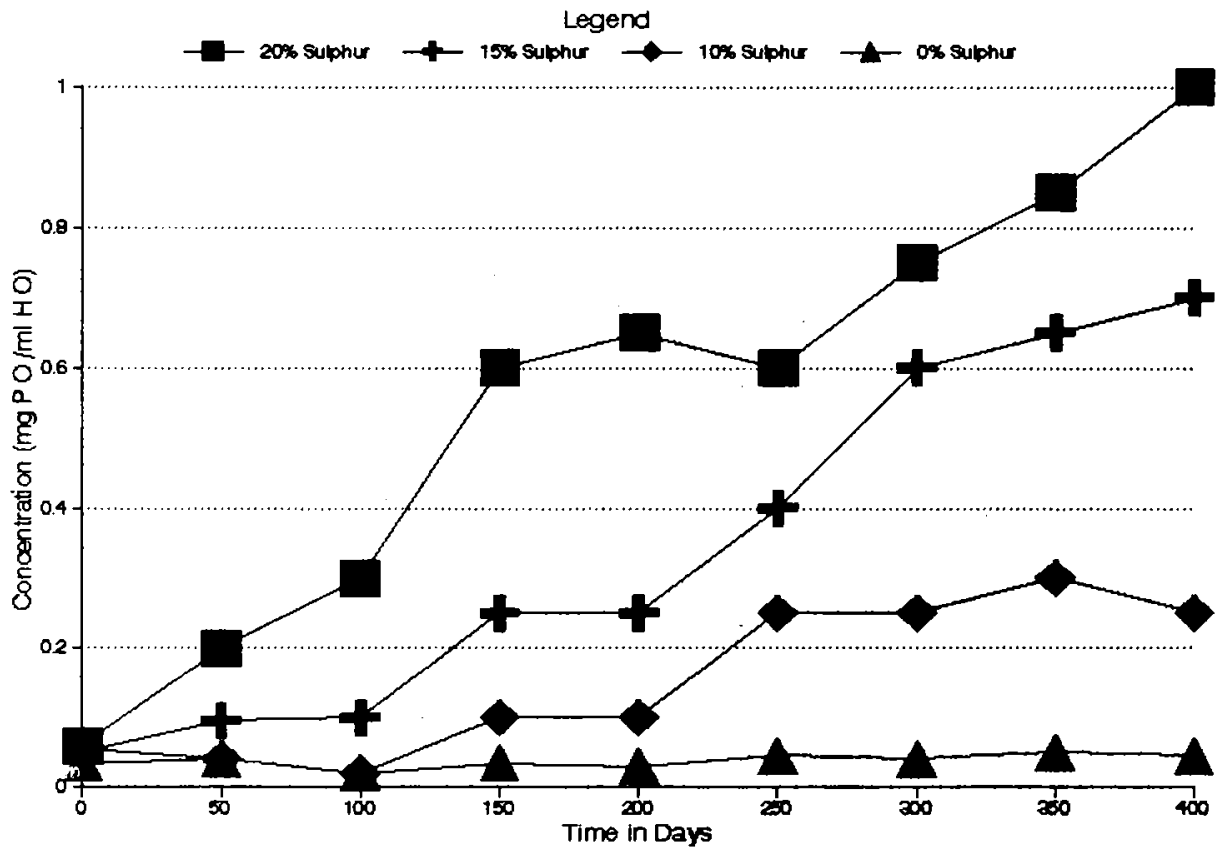

Fig. 2. Diagram showing the increase in concentration of $\mathrm{P}_{2} \mathrm{O}_{5}$ against time

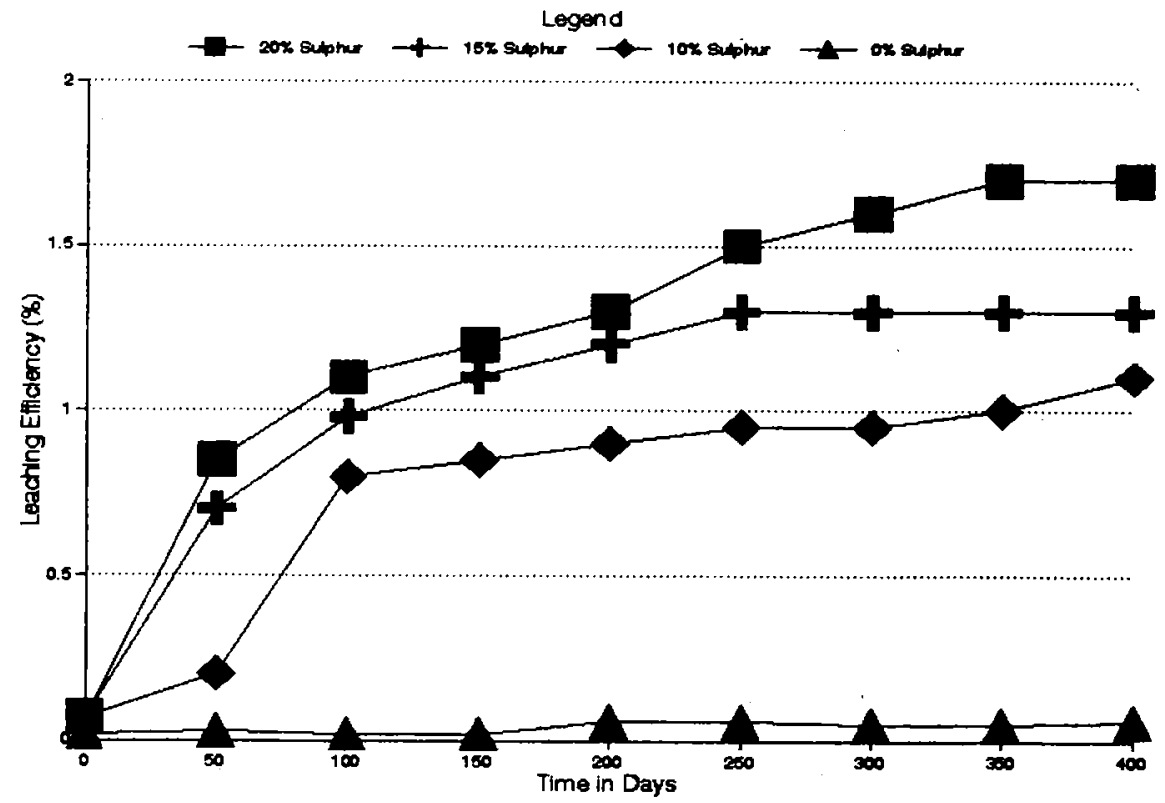

Fig. 3. Diagram showing the increase in the leaching of $\mathrm{P}_{2} \mathrm{O}_{5}$ against time Source: Mbewe, 1991 
1. GRP and elemental sulphur added to the soil separately; sulfuric acid generated from the gradual oxidation of elemental sulphur is directly sorbed by the soil. Little or no portion of it reaches the GRP surface to effect digestion. Depending on quantity of acid evolved or left unneutralized, acidification of soil could here become imminent.

2. GRP and elemental sulphur mixed and added to the soil together; mixtures of this kind in various proportions have been used for fertilization. Their physical appearance differs from that of $\mathrm{PhS}$ in the pattern of elemental sulphur coverage of the GRP surface is not the same. Elemental sulphur is easily removed off the surface of GRP. This type of fertilizer has been found to confer benefits after subsequent cropping seasons (Mokwunye 1975). Technical terms like residual effects have been used to describe such situations though immediate effect had also been observed in instances where GRP was ground finer than usual or precalcinated before mixing. Other works reported, however, very poor agricultural utility of this type of fertilizer mixture.

3. GRP pelleted with elemental sulphur in elevated temperature was named biosuper by Swaby (Urbanek and Ekechukwu 1991). The lumpy feature in appearance suggests that oxygen transport to the core of the pellet might be a rate-limiting step to bio-oxidative activity of the bacteria. Skin surface reaction may only be possible with biosuper.

4. GRP applied alone was found to be of little agricultural utility if the rock phosphate was very soft and sometimes ground to finer particles, smaller than those used in manufacture of traditional fertilizer by wet process.

5. Partially acidulated GRP in dilute solutions of mineral acids could also give allied product similar to $\mathrm{PhS}$ in terms of components. This type of fertilizer has also been found good in agriculture which sometimes extends for multiples of cropping seasons.

Comparison of the $\mathrm{PhS}$ fertilizer with all the above mentioned allied products pin-points sporadic patches of thin films of elemental sulphur on the surface GRP as a distinct physical feature for differentiation of PhS fertilizer from others.

Since sulfuric acid generated biologically is in direct contact with GRP surface, immediate digestion of the GRP could result, preventing instead acidification of the soil in its vicinity. PhS fertilizer could in this way provide both immediate and long term utilities for crops on which it has been used for fertilization. In soil saturated with moisture, $\mathrm{PhS}$ fertilizer can also compare favourably with traditional fertilizers like SSP, TSP, MAP, DAP and/or even nitrophosphate. The high dissolution rate of $\mathrm{P}_{2} \mathrm{O}_{5}$ in these fertilizers could lead to abundance of $\mathrm{P}_{2} \mathrm{O}_{5}$ in the soil but only for a short period of time (Mbewe 1991). Thereafter, only a little fraction determinable by the soil equilibrium condition is left while the rest becomes fixed. Had PhS been used, the gradual release of $\mathrm{P}_{2} \mathrm{O}_{5}$ is accomopanied by its systematic uptake by crops assuring efficient utilization of all the resources employed. 
E k e ch u k w u K., 1990, The PhS fertilizer possibilities for West Africa, Ph.D. thesis, Politechnika Warszawska (Warsaw Technical University).

Mbewe R., 1991, The PhS fertilizer for Zambia. MSc thesis, Politechnika Warszawska (Warsaw Technical University).

Mokw u n y U., 1975, Elemental sulphur as a fertilizer in the Tropics. Soil Sciences Bulletin nr 3. Pergamon Press London.

Urba n e k A,. 1978, Produkcja nawozów fosforowych metodą PhS. Przemyst Chemiczny nr 1. Warszawa.

Urbanek A. and Ekechukwu K., 1991, The leaching efficiency of phosphates through a porous media. Soil Sciences Bulletin nr 3. Pergamon Press London. 